\title{
Yeni Nesil Çevreci Kompozit Traversler
}

\author{
Ozan YAZICI우
TCDD 1. Bölge Müdürlügü, Demiryolu Bakım Servis Müdürlügü, 34716, Kadıköy, Ístanbul, Türkiye
ozanyazici@tcdd.gov.tr

(Alınış/Received: 11.02.2020, Kabul/Accepted: 14.03.2020, Yayımlama/Published: 31.07.2020)

\begin{abstract}
Öz: Dünyanın farklı bölgelerinde birçok kompozit travers teknolojisi geliştirilmiştir. Bu teknolojiler geleneksel traversler olarak nitelenen çelik travers, ahşap travers ve beton traverslere potansiyel bir alternatif olarak ortaya çıkmıştır. Çelik ve betondan farklı olarak kompozit traversler, ahşap travers davranışını taklit edecek şekilde tasarlanabilir ve neredeyse bakım gerektirmeyip, çevresel açıdan daha üstündürler. Bu çalışma kapsamında demiryollarında farklı miktar ve uzunluklarda fiber içeren Tip 1, Tip 2 ve Tip 3 gibi kompozit traversler hakkında bilgi verilerek bu traverslerin kullanımı ve performans karşılaştırılması detaylı olarak yapılmıştır. Kompozit traversler ile konvansiyonel tip olan ahşap, çelik ve beton traverslerin karşılaştırılması yapılmış olup kompozit traverslerin kullanımı sırasında meydana gelen zorluklardan bahsedilerek bu traverslerin demiryollarında geniş çapta kullanım alanı bulabilmesi için hem teknik hem de maliyet açısından ne gibi hususları karşılamaları gerektiği hakkında tavsiyelerde bulunulmuştur.
\end{abstract}

Anahtar kelimeler: Demiryolları, Kompozit, Travers, Yeni Nesil

\section{New Generation Green Composite Sleepers}

Abstract: Many composite sleeper technologies have been developed in different parts of the world. These technologies have emerged as a potential alternative to traditional sleepers which are steel sleepers, wood sleepers and concrete sleepers. Unlike steel and concrete, composite sleepers can be designed to imitate the behavior of wood sleepers, they are virtually maintenance-free and superior in terms of the environment. Within the scope of this study, information about composite sleepers such as Type 1, Type 2 and Type 3 containing different amounts and lengths of fiber on railways were given and the performance and comparison of these sleepers were carried out in detail. Comparison of composite sleepers with conventional types of wood, steel and concrete sleepers was performed, and the difficulties occurring during the use of composite sleepers were mentioned, and recommendations were made on the technical and cost aspects of these sleepers in order to find wide use in railways.

Keywords: Railways, Composite, Sleepers, New Generation

\section{Giriş}

Şekil 1 hat yapısı bileşenlerini göstermektedir. Hat yapısını oluşturan bileşenlerden en önemlilerinden birisi travers olup demiryollarında kullanılan traverslerin esas görevi, ray tekerlek etkileşimi neticesinde demiryolu çeken ve çekilen araçların tekerleklerinden raya gelen tekerlek yüklerini balast ve alt temele transfer etmesi ile rayı tutarak yol ekartmanını korumasıdır. 


\section{Demiryolu Mühendisliği}

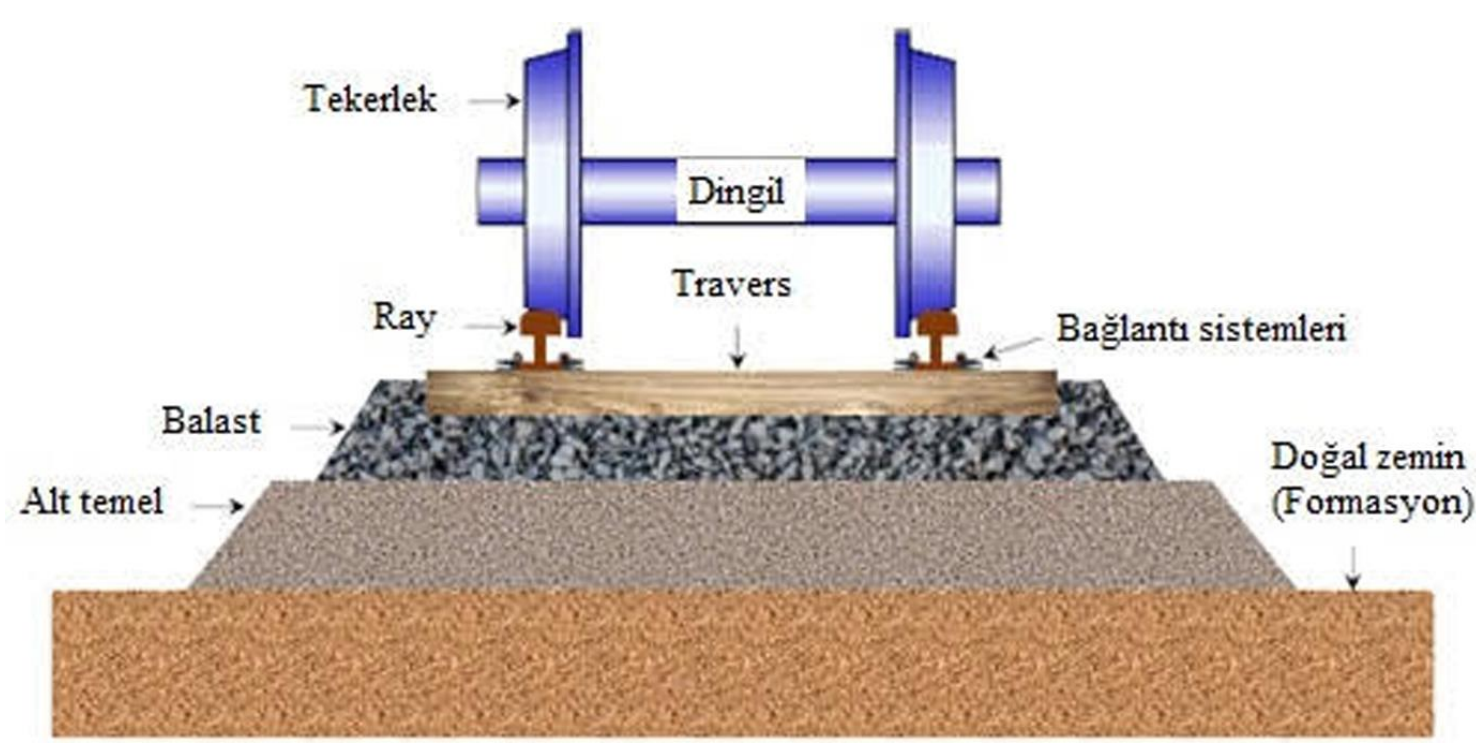

Şekil 1. Hat yapısı bileşenleri

Ahşap, travers malzemesi olarak kullanılan en eski malzeme türüdür [1]. Ahşap traversler hatta kolayca adapte edilebilir ve bu tür traversler yüksek dinamik, elektrik ve ses yalıtımlı özelliklere sahiptirler. 1880'lerde ahşap malzemenin azlığı ve kullanımına karşı duyarlılığın artması neticesinde çelik traversler ahşap traverslere alternatif olarak ortaya çıkmıştır. Son yıllarda ahşap ve çelik traversler yerine demiryolu sektöründe çimento esaslı beton traversler kullanılmaya başlanmıştır. Yekpare gövdeli ön germeli beton traversler ilk olarak 1943 yılında kullanılmaya başlanmış şu anda ise yük ve yolcu taşımacıllğında kullanılan hatlarda yaygın olarak dünya genelinde kullanılmaktadırlar [2]. Tablo 1 ve Tablo 3, demiryolu hatlarında kullanılan çelik, ahşap ve beton traverslere ait genel bilgileri vererek detaylı olarak karşılaştırılmalarını içermektedir.

$\mathrm{Bu}$ durum ise demiryollarında belirli bir travers tipi yerine niçin farklı yapılarda traverslerin kullanıldığı sorusunu doğurmaktadır. Bunun nedeni olarak, hiçbir travers tipinin istenilen gereksinimleri tek başına sağlayamaması olarak açıklanabilir. Kompozit traversler için küresel pazar, bu malzemelerin sahip olduğu yüksek dayanım/ağırlık oranı, korozyona, neme ve böceklere karşı mükemmel direnç ve termal ve elektriksel yalıtkanlık gibi çok önemli avantajlar nedeni ile gittikçe artmaktadır [3]. Kompozit malzeme ayrıca demiryollarındaki özel gereksinimlere göre de tasarlanabilme özelliğine sahiptir [4].

Bu güncel çalışmada, demiryollarında kullanılan geleneksel demiryolu traversleri olan ahşap, çelik ve beton traverslerin kullanımı ile ilişkin bilgiler verilerek bu traverslere alternatif olarak geliştirilen kompozit traverslerin ortaya çıkma gereksinimi, demiryollarında ne tür kompozit travers malzemeleri kullanıldığından detaylı olarak bahsedilerek yeni tip traversler ile geleneksel traverslerin karşılaştırılması yapılmıştır. Bu yeni tip kompozit traverslerin demiryolu ağlarında daha fazla yer bularak kullanımının artabilmesi detaylı olarak tartışılmıştır.

\section{Geleneksel ve Yeni Nesil Demiryolu Traversleri}

Demiryolu traversleri için kullanılan genel malzemeler ahşap, beton ve çelik olup bu materyallerin kullanım ömürleri yaklaşık olarak sırasıyla 20,50 ve 30 yıldır [5-7]. Ahşap kullanımı ile ilgili genel problemler çürüme, yarılma, böcek saldırısı ve aynı zamanda ahşap travers için uygun ağaç bulmada yaşanan zorluklardır. Çelik malzemenin yüksek elektrik iletkenliği, korozyona karşı duyarlılığ ve yorulma çatlağı oluşumu gibi riskler bu malzemenin demiryollarında travers malzemesi olarak kullanımını kısıtlamaktadır. Çelik ve ahşap traverse göre daha dayanıklı olan ön germeli beton travers ise diğer traverslere göre daha ağır olup üretim 


\section{Demiryolu Mühendisliği}

maliyeti daha fazladır ve ayrıca bu traversler düşük darbe basıncına sahip olup kimyasal saldırılara yatkındır. Yüksek ağırlığı nedeniyle taşınması ve kurulum maliyeti diğerlerine göre daha yüksektir [8]. Üstelik beton ve çelik traversler özel ray bağlantı malzemeleri gerektirmekte ve mevcut hatta ahşap travers ile değişimleri uygun olmamaktadır. Beton traversler yüksek dayanıma sahiptirler. Bu traversler gösterdikleri daha yüksek dayanım sebebiyle demiryolu hattında daha yüksek kuvvetlerin transfer etmesine olanak sağlar. Bu durum ise beton traverslerde eğilme çatlakların oluşmasına neden olarak traverste daha fazla bozulmalara sebebiyet vermektedir [9].

Demiryolu traverslerinde meydana gelen potansiyel hatalar üzerinde yapılan bir çalışma [10], geleneksel demiryolu travers malzemelerinin mekanik, biyolojik ve kimyasal bozulmalara karşı istenilen direnci sergileyemediklerini göstermektedir. Olaya çevresel boyutta bakıldığında geleneksel travers malzemeleri bazı problemlere yol açmaktadır. Örneğin ahşap traverslerin üretimi için birçok ağacın kesilmesi durumu söz konusu iken beton ve çelik üretimi için endüstriyel üretim anlamında yüksek miktarda çevreye zarar verici olan $\mathrm{CO}_{2}$ gazı salınımı söz konusudur. Tablo 1 geleneksel traverslerin avantaj ve dezavantajlarını göstermektedir. Tablo 1 de özetlenen geleneksel malzemelere ilişkin problemler demiryollarında yeni nesil travers malzemelerinin geliştirilmesi gereksinimini doğurmuştur.

Tablo 1. Geleneksel travers malzemelerin karşılaştırılması [9, 11]

\begin{tabular}{lllll}
\hline Özellikler & Sert Ăgaç & Yumuşak Ağaç & Beton & Çelik \\
\hline Adapte olabilirlik & Basit & Zor & Zor & Zor \\
İşlene bilirlik & Basit & Basit & Zor & Zor \\
Taşıma ve kurulum & Basit & Basit & Zor & Zor \\
Dayanıklılık & Az & Az & Yüksek & Az \\
Bakım & Yüksek & Yüksek & Az & Yüksek \\
Değiş̧irme & Basit & Basit & Zor & Zor \\
Bulunabilirlik & Düşük & Yüksek & Yüksek & Yüksek \\
Fiyat & Yüksek & Düşük & Çok yüksek & Çok yüksek \\
Bağlantı elemanları ile & İyi & Kötü & Çok iyi & Kötü \\
uyumluluğu & & & & \\
Balast ile etkileşimi & Çok iyi & İyi & Çok iyi & Kötü \\
Elektrik iletkenliği & Düşük & Düşük & Yüksek & Çok yüksek \\
Darbeye karşı direnci & Yüksek & Yüksek & Düşük & Orta \\
Ağırlık (kg) & $60-70$ & $60-70$ & 285 & $70-80$ \\
Servis ömrü (yıl) & $20-25$ & $15-20$ & 50 & 30 \\
\hline
\end{tabular}

\subsection{Yeni nesil kompozit malzemeler}

Özellikle son yirmi yıla bakıldığında, dünyanın farklı yerlerinde çeşitli kompozit travers üretimlerinin gerçekleştiği görülmektedir. Bu kompozit traversler genel anlamda içerdikleri fiber (karbon elyaf) miktarına, uzunluğuna ve konumuna bağlı olarak üç şekilde sınıflandırılmaktadır.

\subsubsection{Tip 1; Fiber takviyesiz veya çok kusa fiber takviyeli traversler}

$\mathrm{Bu}$ tür traversler, geri dönüşümden elde edilmiş plastiklerden (plastik çantalar, hurda araç tekerlekleri, plastik kahve bardakları, plastik süt şişeleri, plastik çamaşır deterjan kutuları vb.) ya da dolgu malzemesi içeren bitümlü malzemelerden üretilmektedir. 


\section{Demiryolu Mühendisliği}

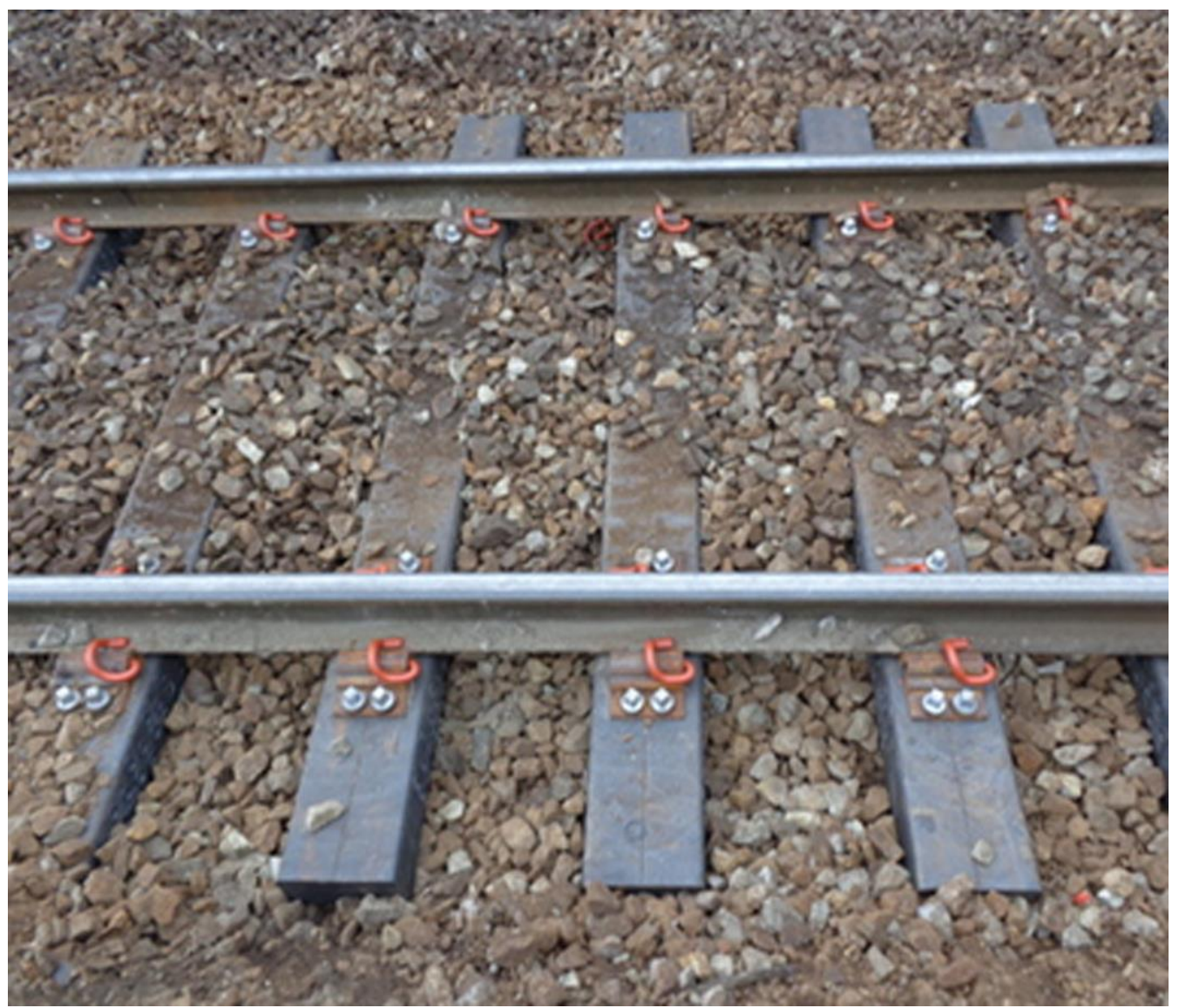

Şekil 2. Fiber takviyeli kompozit traversler [12]

$\mathrm{Bu}$ tip traverslerin yapısal davranışı esasen polimeriktir. Bu teknolojilerin bazıları sertliği ve çatlak oluşumuna karşı direnci arttırıcı kısa cam elyaf içerirken, ağır yük taşımacılığında kullanılan travers uygulamaları için gerekli olan yapısal performansa etki eden takviye etkisine sahip değildirler. Alternatif traverslere olan yüksek talep bazı demiryolu bakım firmalarının bu gibi malzemeleri adapte ederek uygulamasına yol açmıştır. Bu sınıftaki travers malzemeleri, kolay işlenebilme ve kesilebilme, atık malzemelerin tekrardan kullanımı, uygun fiyat ve istenilen sertlik gibi avantajlar sunmaktadır. Endüstriyel anlamda dünyada TieTek, Axion, IntegriCo, IPlas, Tufflex, Kunststof Lankhorst (KLP) gibi firmalar bu tür travers üretimini gerçekleştirmektedir.

\subsubsection{Tip 2; Boyuna yönde uzun fiber içeren kompozit traversler}

$\mathrm{Bu}$ tip traversler, boyuna yönde, uzun sürekli cam fiber takviyesi içeren traversler olup enine yönde ise içerisinde fiber bulunmayan ya da kısa rastgele yönde dağılmış fiber bulunan bir yapıdan oluşmaktadır. Boyuna yönde mukavemet ve sertlik, başlıca uzun cam fiber tarafından sağlanmakta iken enine yönde ise polimer tarafindan bu durum domine edilmektedir. Bu tip traversler balastlı yollarda eğilme yükü altında gerilmelere maruz kalan traversler için uygundur. Kolay işlenebilirliği, kesilebilirliği, iyi dayanıklılı̆̆ı, üstün eğilme mukavemeti ile yüksek elastisitesi bu tip traverslerin en önemli özellikleridir. Fiber katkılı köpüklü üretan sentetik traverslerde (FFU) bu sinıf travers sinıfi kapsamındadır [13-15]. Bu tip traverslerin en önemli özelliği düşük ağırlığı, su emmeye, 1s1 ve korozyona karşı iyi direnç göstermesi, kolay işlenebilirliği ve 50 yıldan fazla kullanım ömrünün olmasıdır. Bu tip traversler demiryolu hatlarında, makaslarda ve köprülerde başarılı bir şekilde kullanılmaktadır [16]. 


\section{Demiryolu Mühendisliği}
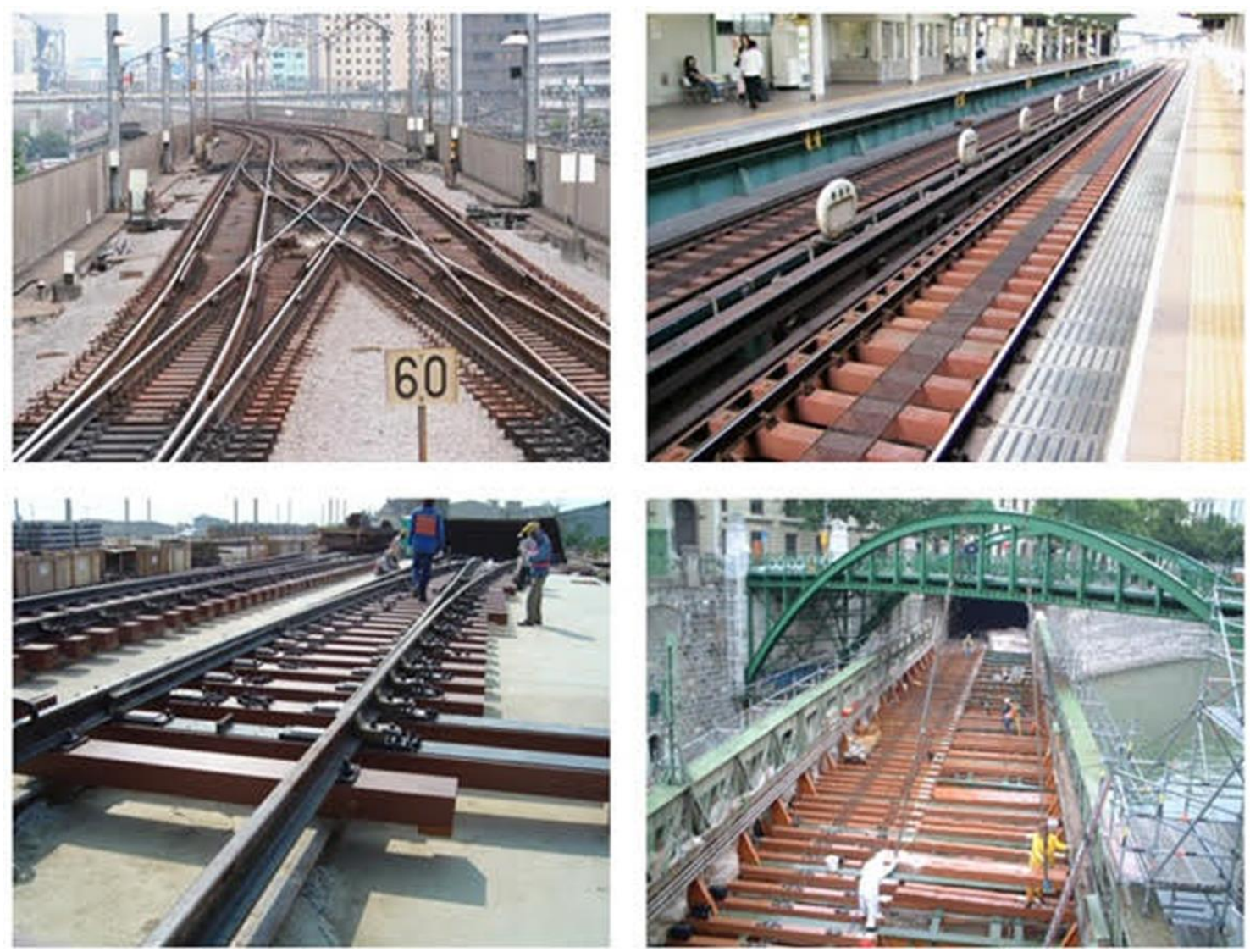

Şekil 3. Fiber katkılı köpüklü üretan sentetik travers uygulaması [17]

Dünya genelinde Japonya, Almanya, Hollanda Avusturya, Tayvan ve Amerika'da bu tip kompozit malzemeler başarılı bir şekilde kullanılmakta olup ayrıca Çin'de uygulamaları üzerine çalışmalar devam etmektedir [18].

\subsubsection{Tip 3; Boyuna ve enine yönde fiber içeren kompozit traversler}

$\mathrm{Bu}$ tip traversler hem boyuna hem de enine yönde uzun takviyeli fiber içermekte olup traversin eğilmeye ve kesmeye karşı davranışı fiberler tarafından domine edilmektedir. Bu traversin yapısal performansı arzu edilen performans gereksinimlerine göre istenilen yönde fiber takviyesi ile ayarlanmaktadır. Fiberlerin her iki yönde de yönlendirildiği sandviç polimer travers ve hibrit kompozit traversler bu tip travers kapsamındadırlar [19-21]. 


\section{Demiryolu Mühendisliği}

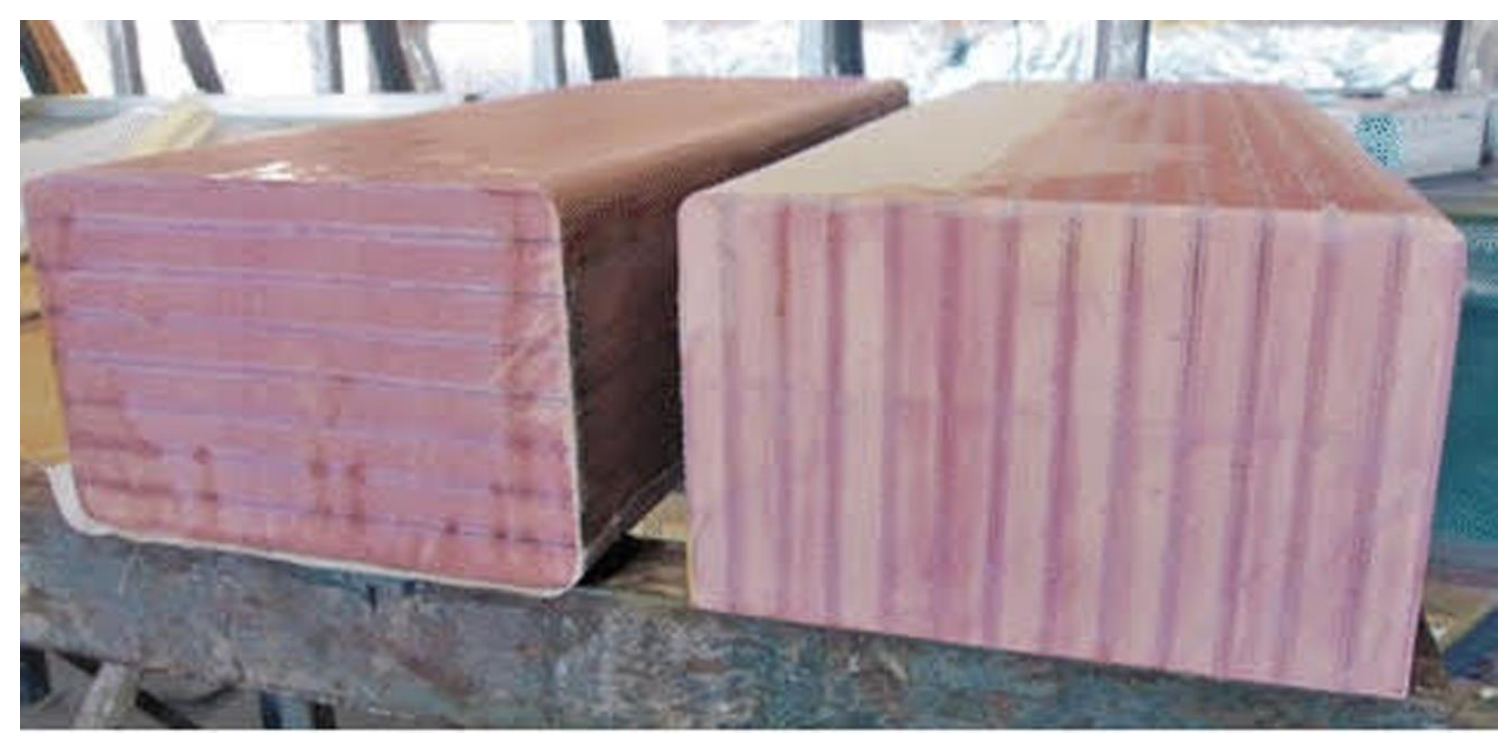

Şekil 4. Lamine kompozit travers [22]

Tablo 2'de Tip 1, Tip 2 ve Tip 3 kompozit traverslerin göstermiş oldukları performans özellikleri hakkında bilgiler sunulmaktadır.

Tablo 2. Tip 1, Tip 2 ve Tip 3 kompozit traverslerin tipik özellikleri [23]

\begin{tabular}{llll}
\hline Özellikler & Tip 1 & Tip 2 & Tip 3 \\
\hline Yoğunluk $\left(\mathrm{kg} / \mathrm{m}^{3}\right)$ & $850-1150$ & 740 & $1040-2000$ \\
Elastisite Modülü, $(\mathrm{GPa})$ & $1,5-1,8$ & 8.1 & $5,0-8,0$ \\
Kirılma Modülü, (MPa) & $17,2-20,6$ & 142 & $70-120$ \\
$\begin{array}{l}\text { Kesme mukavemeti, (MPa) } \\
\text { Ray oturma alanı basma kuvveti, } \\
\text { (MPa) }\end{array}$ & $15,2-20,6$ & 10 & $15-20$ \\
Tirfon tutma mukavemeti, $(\mathrm{kN})$ & $31,6-35,6$ & 65 & 40 \\
\hline
\end{tabular}

Tablo 3’te ise köprülerde kullanılan geleneksel ve yeni nesil traverslerin karşılaştırılması hakkında bilgi vermektedir.

Tablo 3. Köprü traverslerinin karşılaştırılması [5, 7, 24]

\begin{tabular}{lccc}
\hline & Ahşap & Çelik & Kompozit \\
\hline Kullanım ömrü (Yıl) & 20 & 30 & $>50$ \\
Travers tebdili & Kolay & Zor & Kolay \\
Elleçlenmesi & Çok kolay değil & Zor & Kolay \\
\hline
\end{tabular}

Kompozit traverslere ait boyutsal, fiziksel, mekanik ve elektriksel özellikler ISO 12856-1 [25] ve AREMA [26] standartlarında detaylı bir şekilde verilmektedir.

\section{Tartışma ve Sonuç}

Geleneksel olarak kullanılan ahşap, çelik ve beton traverslerin dizayn ve sergileyecekleri kalite ile ilgili gereksinimler ilgili standartlarda detaylı olarak verilmekte olup kompozit traverslere ait genel bilgiler ise hem ISO 12856-1 [25] standardında hem de Amerikan Demiryolu Mühendisliği ve Yol Bakım Birliği (AREMA) [26] tarafından hazırlanan standartlarda belirtilmektedir. Kompozit traverslerin, ahşap traverslere göre daha yüksek maliyetli olması demiryollarında kullanımı açısından önemli bir husustur. Ancak kullanım ömrü düşünüldüğünde fiyatı kendini kompanse etmekte ve geleneksel ahşap traverse göre daha üstün kılmaktadır [27-29]. Konu hakkında yapılan araştırmalar [30, 31], kompozit traversin yapısal boyutlandırılmasının optimize 


\section{Demiryolu Mühendisliği}

edilmesi ile bu şekilde kullanılan malzemenin miktarını azaltılarak maliyetin düşürülebileceği yönündedir. Tip 1 kapsamında kullanılan malzemelerdeki plastik oranı geleneksel olarak şekillendirilmiş katı traverslere göre hacimce \% 35 azaltılarak optimize edilmiştir. Kullanılan malzemedeki bu optimizasyon sadece maliyet açısından önem arz etmemekte ayrıca sahip olduğu uniform olmayan şekli nedeniyle traversin hattaki yanal stabilitesini arttırmas1 açasından önem arz etmektedir [32]. Optimize edilmiş olan travers Şekil 5' te gösterilen tekerlek yük dağılımına bağlı olarak dizayn edilebilir.

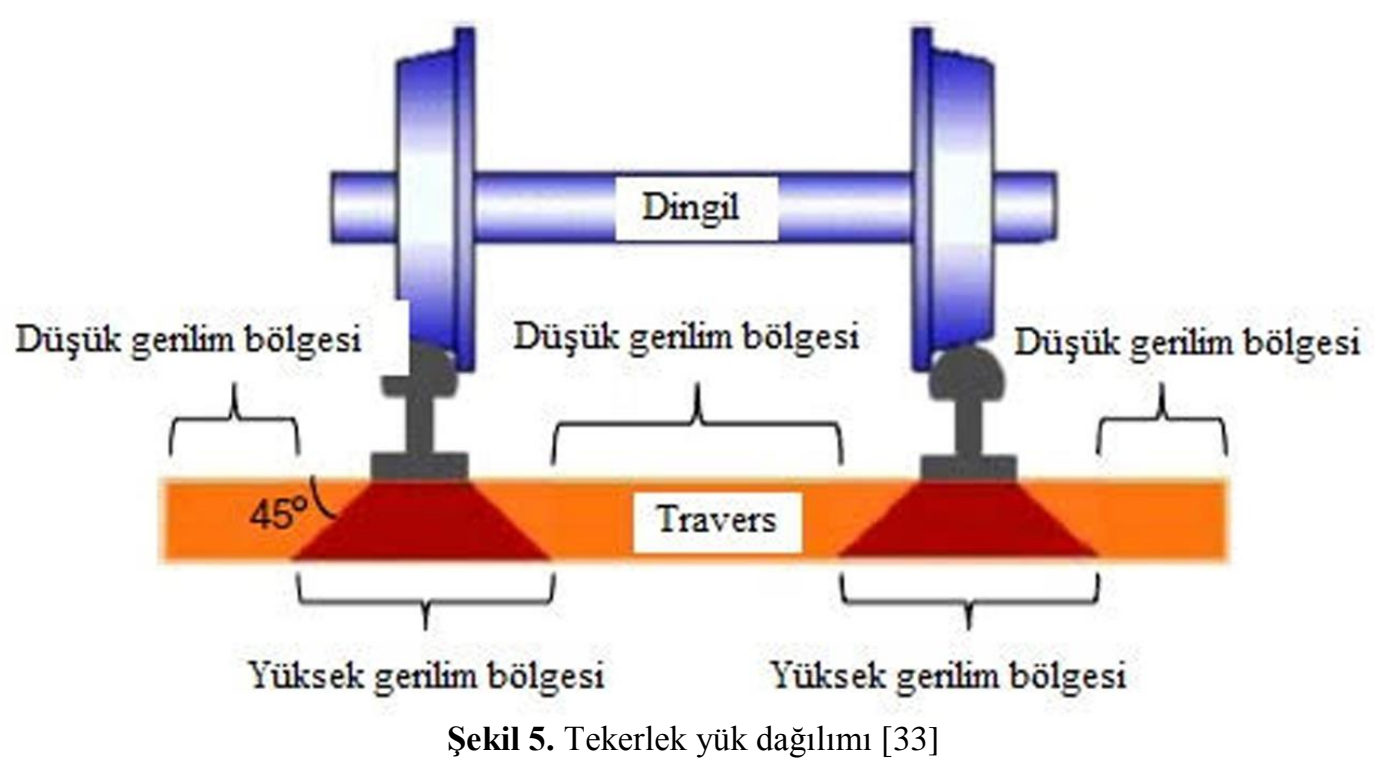

Çoğu kompozit travers üreticileri traverslerin statik performansını değerlendirmesine rağmen bu traverslerin uzun vadede dinamik performans, darbe dayanımı, yorulma ve dayanıklılık ile ilgili özellikleri hala tam olarak bilinmemektedir.

Kompozit malzemelerin performansı tren trafiği altındaki yük gereksinimlerini karşılama yanında, UV radyasyon, yüksek $\mathrm{pH}$, yüksek ve düşük sıcaklık, nem ve benzeri çevresel faktörlere karşı koyma kabiliyetlerine de bağlıdır. Yeni nesil kompozit traversler diğer geleneksel traverslere nazaran demiryolları açsısından yeni bir teknolojidir [34, 35]. Bu yüzden bu traverslerin hem kısa hem de uzun vadede performanslarının incelenerek bu malzemelerin geliştirilmesi ve kullanımına ilişkin güvenirliliğinin artırılması çalışmaları önem arz etmektedir.

Kompozit traversler demiryolu hat bakım ve yenileme çalışmalarında kullanılan geleneksel traverslere özellikle ahşap traverslere alternatif bir malzeme olarak ortaya çıkmıştır. Yeni nesil kompozit traverslerin sahip oldukları yüksek dayanım/ağırlık oranı, korozyon, nem ve böcek atağına karşı gösterdikleri mükemmel direnç, termal ve elektriksel yalıtkanlık gibi üstün dikkat çekici özellikleri sebebiyle tüm dünyada bu tip yeni nesil traverslerin demiryollarında hatlarında, makaslarda ve demiryolu köprülerindeki kullanımına ilişkin kullanımı hakkında araştırma ve geliştirme çalışmaları devam etmektedir.

Kompozit traverslerin diğer önemli bir yanı ise bu travers tipinin çevresel açıdan diğer traverslere göre daha üstün olmasıdır. Kompozit malzememler artık plastik malzemelerin geri dönüşüm teknolojisi ile geri kazanımı ile üretilebilmektedir. Ahşap traverslerin üretilebilmesi için birçok ağacın kesilmesine ihtiyaç duyulmakta ayrıca işlenip son mamul olarak ortaya çıkması sırasında çevreye ve insan sağlığına zararlı olan kreozot ile muamele görmektedirler. Beton ve çelik travers üretimlerinde ise endüstriyel üretim anlamında yüksek miktarda çevreye zarar verici olan $\mathrm{CO}_{2}$ gazı salınımı söz konusudur. Kompozit traverslerin üretimi kapsamında bu gibi zararlı gaz 


\section{Demiryolu Mühendisliği}

salınımının olmaması ve tekrardan kullanılabilirliği neticesinde hem çevreye hem de insan sağlığı üzerine olumlu etkilerinin olacağı düşünülmektedir.

Yüksek lamel içeren kompozit traverslerin yüksek maliyetini azaltabilmek için kullanılan malzeme miktarı ve üretim prosesinin geliştirilmesi hakkında optimizasyon çalışmaları devam etmektedir. Bu tür traversler her ne kadar dünyanın birçok yerinde uygulama alanı bulmuş olsa da demiryollarında geniş çapta kullanımı ve kabul edilebilirliği dinamik etki ve yorulma davranışları, dayanıklılık ve çevresel boyutları, toplam işletme masrafları analizleri, yıllara bağlı olarak hattaki performansları gibi bilgileri içeren standart ve teknik verilerin elde edilmesi ile mümkün olacaktır.

\section{Kaynakça}

[1] Corbat-Holding, "History and development of the wooden sleeper" February, 2020. [Online]. Available: www.corbat-holding.ch. [Accessed February 18, 2020].

[2] S. Kaeunruen, "Sleepers and fastenings", Track Design Fundementals, Rail Engineering Course, Rail Corporation, 2010.

[3] HVS. GangaRao, N.Taly, PV. Vijay, Reinforced concrete design with FRP composites. CRC Press, 2007.

[4] G. Van Erp, M. Mckay, "Recent australian developments in fibre composite railway sleepers". Electronic Journal of Structural Engineering, vol:13(1), no:62-6, 2013.

[5] R.H. Crawford, "Greenhouse gas emissions embodied in reinforced concrete and timber railway sleepers", Environmental Science \& Technology, vol:43, no:10, pp. 3885-3890, 2009.

[6] Concrete Sleepers, RailCorp Engineering Specification, SPC 232, 2012.

[7] Steel Sleepers usage and installation standards TCS 10 Engineering (Track), ARTC, 2009.

[8] G. Van Erp, C. Cattel, T. Heldt, "Fibre composite structures in Australia's civil engineering market: an anatomy of innovation", Structural Engineering and Materials, vol:7, no:3, pp. 150-160, 2005.

[9] A. Manalo, T. Aravinthan, W. Karunasena, A. Ticoalu, "A review of alternative materials for replacing existing timber sleepers”, Composite Structures, vol:92, no:3,pp.603-611, 2010.

[10] W. Ferdous, A. Manalo, "Failures of mainline railway sleepers and suggested remedies-Review of current practice, Engineering Failure Analyses, vol:44, pp.17-35, 2014.

[11] S. Kaewunruen, R. You, M. Ishida, "Composites for timber-replacement bearers in railway switches and crossings, Infrastructures, 2017.

[12] Prnewswire, "composite sleepers", February, 2020. [Online]. www.prnewswire.com/news [Accessed February 18, 2020].

[13] H. Takai, Y. Sato, K. Sato, "Japanese twenty five years experiences and standardization of synthetic sleepers". [Online]. Available: http://www.railway-research.org/IMG/pdf/589.pdf [Accessed February $18,2020]$.

[14] S. Kaewunruen, "Acoustic and dynamic characteristics of a complex urban turnout using fibrereinforced foamed urethane (FFU) bearers", International Workshop on Railway Noise, 2013.

[15] Sekisuichemical, "Products, $\quad$ February, 2020.2 [Online]. https://www.sekisuichemical.com/company/japan/index.html [Accessed February 18, 2020].

[16] G. Koller, "The use of sleepers made of FFU snthetic wood in europe, RTR, 2009.

[17] Sekisuichemical," "FFU synthetic railway sleepers, February, 2020. [Online]. https://www.sekisuichemical.com/company/japan/index.html [Accessed February 18, 2020].

[18] A.S. Liu, D. Yin, G. Liu, “ A study on application of resin composite sleeper in design of long-span rail bridges", Sustainable Transportation Systems, 2012.

[19] A.C. Manalo, T. Aravinthan, "Behaviour of fullsclae railway turnout sleepers from gluelaminated fibre composite sandwich sructures", ASCE Journal of Composite for Construction, vol: 16, no:6, pp.724736, 2012. 


\section{Demiryolu Mühendisliği}

[20] W. Ferdous, A. Manalo, A. Khennane, O. Kayali, “Geopolymer concrete-filled pultruded composite beams-concrete mix design and application”, Cement and concrete composites, vol: 58, pp.1-13, 2015.

[21] W. Ferdous, A. Manalo, A. Khennane, O. Kayali, "Hybrid FRP-concrete railway sleeper", 6th International conference on advanced composites in construction, Belfast, UK, 10-12 Sep.2012.

[22] Google, "Laminated composite sleepers", February, 2020. [Online]. www.google.com/search [Accessed February 18, 2020].

[23] W. Ferdous, A. Manalo, T. Aranvinthan, A. Remennikov, “ A recent developments and applications of composite railway sleepers, 2016.

[24] A. Ghorbani, S. Erden, "Polymeric composite railway sleepers", 2. Uluslararası Rayll Sistemler Mühendisliği Sempozyumu, 2013.

[25] Plastics-Plastic railway sleepers for railway applications (railroad ties)-Part 1: Material characteristics, ISO 12856-1 Standard, 2014.

[26] Manul for 542 Railway Engineering, AREMA(American Railway Engineering and Maintenance-ofway Association), 30, 2006.

[27] Axionintl, “Axion Ecotrax composite railroad ties”, February, 2020. [Online]. www.axionintl.com [Accessed February 18, 2020].

[28] In, "Integrico compositetegricos, February, 2020. [Online]. www.integrico.com [Accessed February $18,2020]$.

[29] V.P. McConnell, "Rail-an evolving market for FRP components”, Reinforced Plastics, pp.24-29, 2008.

[30] T. Nosker, R. Renfree, J. Lynch, M. Lutz, B. Gillespie, K.E.Van Nes, et al, "A performance based approach to the development of a recycled plastic/composite crosstie". [Online]. Available: file://C:/Users/00002570/Downloads/A_PerformanceBased_Approach_to_the_Development_of.pdf [Accessed February 18, 2020].

[31] L.C.Bank, Composites for construction: structural design with FRP materials. New Jersey: John Wiley\&Sons, 2006.

[32] K. Hayano, Y. Koike, T. Nakamura, Y. Momoya, "Effects of sleepers shape on lateral resistance of railway ballasted tracks", Advnaces in soil dynamic and Foundation Engineering, 2014.

[33] W. Ferdous, A. Manalo, G. Van Erp, T. Aravinthan et al., "Evaluation of an Innovative Composite Railway Sleeper for a Narrow-Gauge Track under static load ", Jornal of Composites for Cosntruction, vol:2, no:2, 2018.

[34] A. Manalo, M. Muttashar, P. Yu, R. Kakarla, "Composites for alternative railway sleepers”, 2019. [Online]. Available: works.bepress.com [Accessed March 05, 2020].

[35] É.A. Silva, D. Pokropski, R. You, Comparison of structural design methods for railway composites and plastic sleepers and bearers. Taylor \& Francis, 2017.

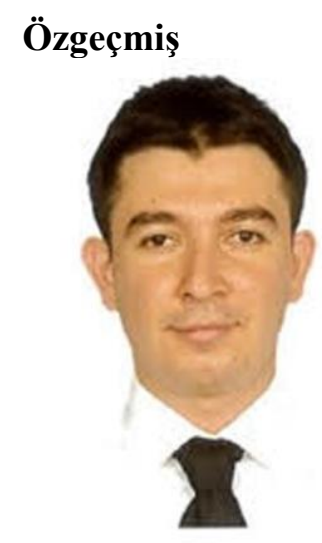

Beyanlar

\author{
Ozan YAZICI \\ 1983 yılında İstanbul'da doğmuştur. Lisans, Yüksek Lisans \\ ve Doktora Eğitimlerini İstanbul Üniversitesi Metalurji ve \\ Malzeme Mühendisliği Bölümünde tamamlamıştır. İstanbul \\ Üniversitesinde Deniz Ulaştırma ve İşletme Mühendisliği \\ Bölümünde ayrıca Yandal yapmıştır. TCDD bursiyeri \\ olarak ikinci Yüksek Lisansını İngiltere'de Birmingham \\ Üniversitesinde Demiryolu Sistem Mühendisliği ve \\ Integrasyon üzerine yapmıştır. 2013 Yılından beri TCDD 1. \\ Bölge Müdürlüğü Demiryolu Bakım Servis Müdürlügünde \\ çalışmaktadır. \\ E-Posta: ozanyazici@tcdd.gov.tr
}

Bu makalede bilimsel araştırma ve yayın etiğine uyulmuştur. 